\title{
Numerical hull resistance calculation of a catamarán using OpenFOAM
}

DOI: $10.25043 / 19098642.150$

Diana S. Hurtado Bustos ${ }^{1}$

Rubén J. Paredes Alvarado ${ }^{2}$

\begin{abstract}
In the present study, numerical resistance predictions using OpenFOAM were performed considering the Cormorant Evolution Catamaran, which provides travel services in the Galapagos Islands. These predictions were compared with experimental data published by Chávez and Lucín [1] and with systematic series [2]. Simulations were made at model scale of $2[\mathrm{~m}]$ in two load conditions, considering demi and twin hull $(\mathrm{s}=0.56[\mathrm{~m}])$ configurations. A mesh convergence study was performed with 3 different meshes for $\mathrm{V}=1.05[\mathrm{~m} / \mathrm{s}]$ at Light Condition $(\mathrm{T}=0.086[\mathrm{~m}])$. The converged mesh, with 1 million of cells approximately, has the lower standard deviation and a 5\% error when compared to its experimental value of $1.79[\mathrm{~N}]$. The errors between the experimental data and the numerical simulations for demi hull configuration were $43 \%$ and 36\% for Light and Full conditions, respectively. Besides, for twin hull configuration the errors were around $14 \%$ and $32 \%$ for Light and Full conditions, respectively.
\end{abstract}

Key words: Catamaran, CFD, resistance, interference.

\section{Resumen}

En el presente estudio, predicciones numéricas de resistencia usando OpenFOAM fueron realizadas considerando el Catamarán "Cormorant Evolution", que ofrece servicios turísticos en las Islas Galápagos. Las predicciones numéricas fueron comparadas con datos experimentales publicados por Chávez y Lucín [1], y con métodos estadísticos [2]. Las simulaciones fueron realizadas con un modelo de 2[m] en dos condiciones de carga, considerando uno y los dos cascos $(s=0.56[\mathrm{~m}])$. Se realizó un estudio de convergencia con tres mallas para $\mathrm{V}=1.05[\mathrm{~m} / \mathrm{s}]$ en condición ligera $(\mathrm{T}=0.086[\mathrm{~m}])$. La malla seleccionada contiene alrededor de 1 millón de celdas y presenta un error del $5 \%$ frente a una resistencia experimental de $1.79[\mathrm{~N}]$. El promedio de los errores entre datos experimentales y simulaciones numéricas para un casco son del $43 \%$ y $36 \%$ para condición ligera y cargada, respectivamente. Por otro lado, los errores para dos cascos son del 14\% y $32 \%$ para condición ligera y cargada, respectivamente.

Palabras claves: Catamarán, CFD, resistencia, interferencia.

Date Received: February 24th 2017 - Fecha de recepción: Febrero 24 de 2017

Date Accepted: March $10^{\text {th }} 2017$ - Fecha de aceptación: Marzo 10 de 2017

\footnotetext{
${ }^{1}$ Escuela Superior Politécnica del Litoral. Guayaquil, Ecuador. Email: dshurtad@espol.edu.ec
}

${ }^{2}$ Escuela Superior Politécnica del Litoral. Guayaquil, Ecuador. Email: rparedes@espol.edu.ec 


\author{
Abbreviations \\ CFD Computational Fluid Dynamics \\ Exp Experimental \\ OF OpenFoam \\ RANS Reynolds Average Navier-Stokes \\ Rt Total Resistance in Newtons [N] \\ $S \quad$ Separation distance between the hulls (m). \\ Sta. Dev. Standard Deviation \\ $T \quad$ Model draft (m) \\ $V \quad$ Velocity of the simulation fluid $(\mathrm{m} / \mathrm{s})$
}

\section{Introduction}

The resistance of a ship at a given speed is the force required to tow the ship at that speed in calm water, assuming no interference from the towing ship [3]. The ship must provide the minimum shaft horsepower to cruise at required velocity.

Ship resistance estimation is a complex task. It can be broken down into frictional and residual components. In addition, there is an additional component in the case of catamarans, such as the interference between the demi-hulls. There are three different methods to predict ship resistance: empirical methods, model testing and numerical simulations.

In the last years, numerical simulations using CFD have become a third alternative used in the industry. The CFD solution is a numerical method to solve the nonlinear differential equations governing the fluid flow. However, it cannot be used as a black box because it can produce spurious results if not set correctly. It is required to perform a verification and validation procedure, usually using experimental data.

In this work, numerical simulations were performed to predict total resistance of a catamaran and results were validated using experimental data obtained by Chávez and Lucín [1]. OpenFOAM is used to predict the catamaran resistance. It was chosen because of its customization options, online training and support, and it is open source.

\section{Geometry and test conditions}

The "Cormorant Evolution" Catamaran was built in Ecuador in 2011 by "Astilleros y Marina BOTTO CIA. LTDA", and operates through "Cormorant Cruise" in Galapagos Islands [4]. It is a $32.5[\mathrm{~m}]$ length fiberglass touristic vessel; with a "V" middle section, a bulbous bow, separation of $9.11[\mathrm{~m}]$ between the centerlines of hulls and a design velocity of 5.14 meters per second (10 knots). Subsequently a $2[\mathrm{~m}]$ length model was built using Cormorant Evolution hull-shape, to measure experimental resistance in the lake of "Escuela Superior Politécnica del Litoral" (ESPOL) [1]. The scale factor was $\lambda=16.25$. The experiment velocity range of the model was from 1.05 to 1.45 meter per second. Table 1 shows the main characteristics of the catamaran at two load conditions.

\section{Computational method}

Open Source Field Operation and Manipulation (OpenFOAM) is a free source code with $\mathrm{C}++$ programing language. This code creates executable

Fig. 1. Experimental test at ESPOL Lake

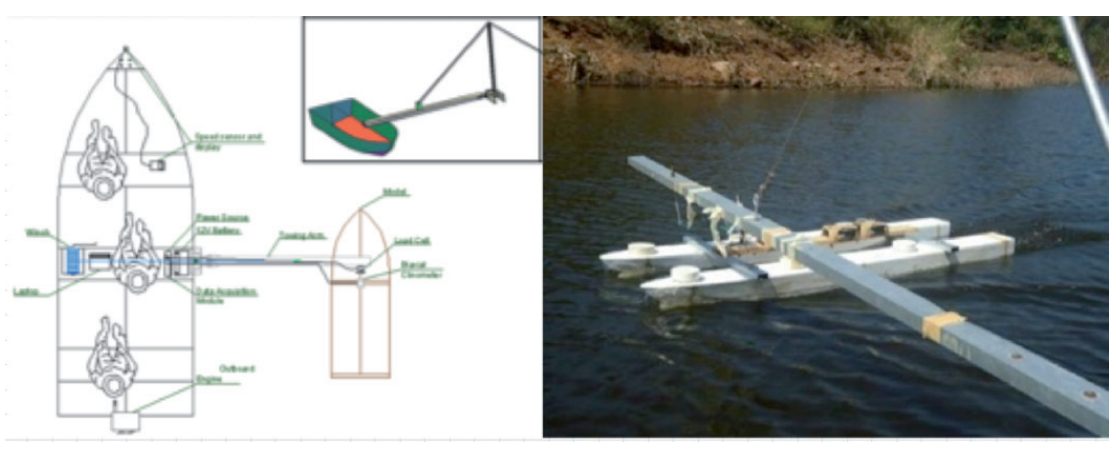


Table 1. Catamaran scale model dimensions

\begin{tabular}{lrr} 
& \multicolumn{1}{c}{ Light Load } & \multicolumn{1}{c}{ Full Load } \\
\hline $\mathrm{L}[\mathrm{m}]$ & 2.00 & 2.00 \\
\hline Bcat $[\mathrm{m}]$ & 1.87 & 1.89 \\
\hline $\mathrm{S}[\mathrm{m}]$ & 0.561 & 0.561 \\
\hline $\mathrm{T}[\mathrm{m}]$ & 0.086 & 0.103 \\
\hline$\Delta[$ ton $]$ & 0.018 & 0.024 \\
\hline
\end{tabular}

scripts, called applications that are divided in two categories: solvers developed for specific problems in continuum mechanics, and utilities developed to manipulate data. Fig. 2 shows the workflow of OpenFOAM.

There are three physical laws that govern a fluid flow: Conservation of Mass, Conservation of momentum, and Newton's Second Law. However, these equations cannot be solved analytically for all types of problems.

One alternative is to solve them numerically using Computational Fluid Dynamics (CFD). In real applications, fluids flow is turbulent and it can be modeled by RANS technique. The governing equations are:
Reynolds Average Navier-Stokes

$\rho \frac{\partial U_{i}}{\partial t}+\rho U_{i} \frac{\partial U_{i}}{\partial x_{j}}=-\frac{\partial P}{\partial x_{i}}+\frac{\partial}{\partial x_{j}}\left(2 \mu s_{i j}-\overline{\rho u_{j}^{\prime}} \overline{u_{l}^{\prime}}\right)$

For linear eddy viscosity models, RANS need some extra terms (transport properties) to represent the turbulence properties of the flows. In this work turbulence is modeled using the k-Omega SST method, which is a two-equation linear eddyviscosity model.

Turbulence kinetic energy

$\frac{\partial k}{\partial t}+U_{j} \frac{\partial k}{\partial x_{j}}=P_{k}-\beta^{*} k \omega+\frac{\partial}{\partial x_{j}}\left[\left(v+\sigma_{k} v_{T}\right) \frac{\partial k}{\partial x_{j}}\right]$

Specific dissipation rate

$$
\begin{array}{r}
\frac{\partial \omega}{\partial t}+U_{j} \frac{\partial \omega}{\partial x_{j}}=\alpha S^{2}-\beta \omega^{2}+\frac{\partial}{\partial x_{j}}\left[\left(v+\sigma_{\omega} v_{T}\right) \frac{\partial \omega}{\partial x_{j}}\right] \\
+2\left(1-F_{1}\right) \sigma_{\omega 2} \frac{1}{\omega} \frac{\partial k}{\partial x_{i}} \frac{\partial \omega}{\partial x_{i}}
\end{array}
$$

Fig. 2. OpenFoam Workflow

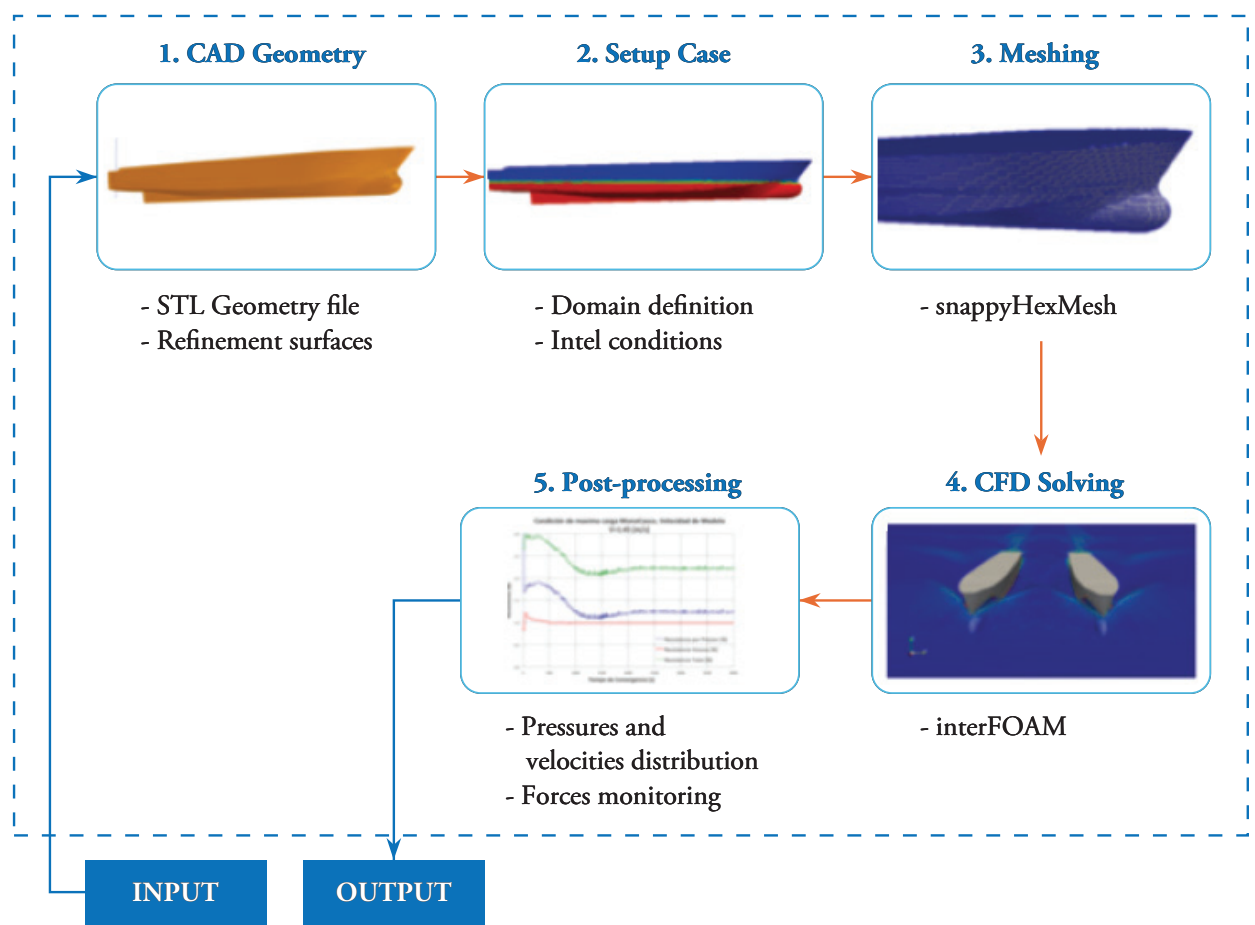


The following assumptions about the numerical model to be implemented are considered:

i. Steady, turbulent and three-dimensional flow.

ii. Single-phase flow.

iii. Uniform velocity.

iv. Constant air and water properties.

For marine applications, two solvers can be used for multiphase flows, interFoam and interDyFoam. In this thesis, the InterFoam solver is applied because only ship resistances are measured in experiments. InterFoam is a solver for two incompressible, isothermal immiscible fluids using a volume of fluid phase-fraction based interface capturing approach [8]. The computational domain includes fresh water and atmosphere.

$y^{+}$is the non dimensional distance and OpenFOAM is a post processing tool applied to near-wall cells of all wall patches. The value obtained by $y^{+}$can describe the places where the mesh has to have a greater number of cells. $y^{+}$is defined by:

$$
y^{+}=\frac{u_{*} y}{v}
$$

Where $u_{*}$ is the frictional velocity at the nearest wall, $y$ is the distance to the nearest wall and $v$ is the local kinematic viscosity of the fluid.

\section{Results}

\section{D Generation model}

The 3D surface model was generated with the body and profile plan in the Computer Aided
Design (CAD) software Rhinoceros 3D [5] and positioned after the perpendicular line at the origin axes before exporting as a STL file to import into the CFD code, OpenFOAM. Fig. 3 shows the 3D Rhinoceros scaled demi-hull model.

\section{Domain, grids and boundary conditions}

The computational domain was built as a rectangular block around the hull (demi and twin hulls) in deep water; Fig. 4 shows the principal dimensions in meters.

Fig. 4. Catamaran domain size

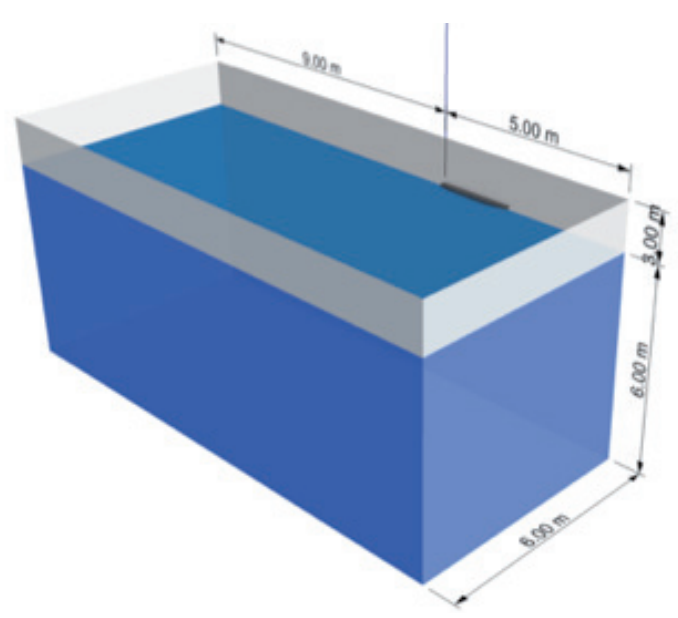

\section{Verification and validation}

To identify the mesh density needed for the Catamaran cases a mesh convergence study was perform. The domain was divided into six blocks with different mesh densities. Table 2 shows the number of cells for each mesh.

To visualize the convergence of the simulations, Fig. 5 shows the force time history $(4,000$

Fig. 3. Scale Cat. 3D model

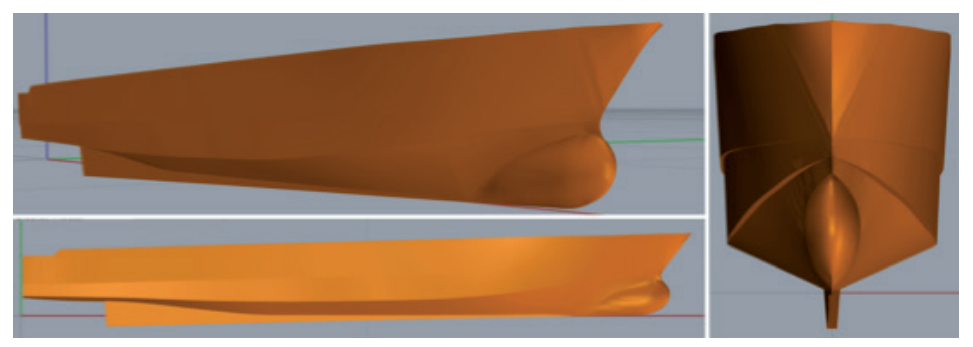


Fig. 5. Total Resistance along the setting time of convergence for different mesh densities

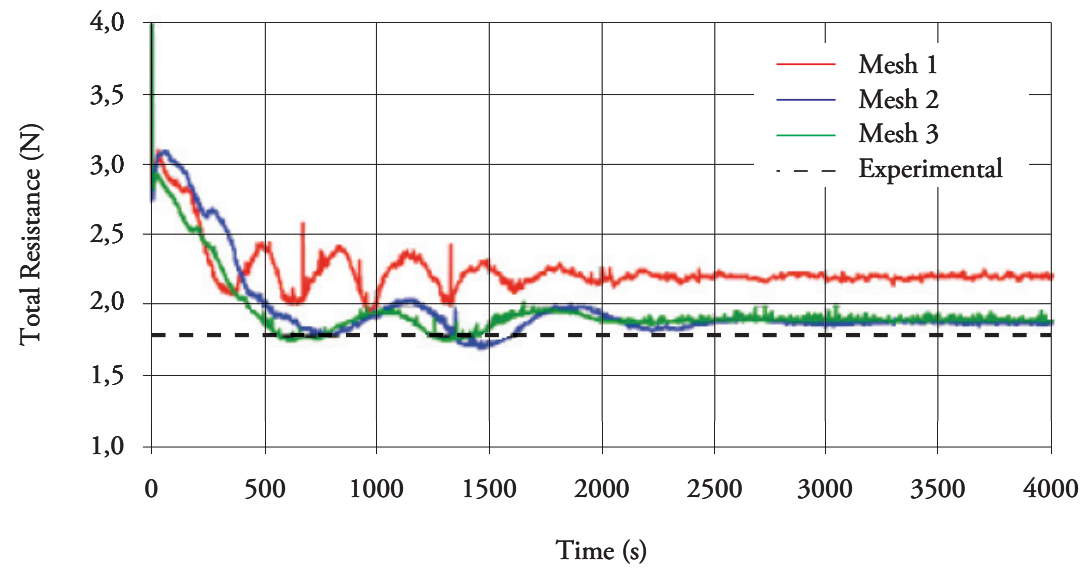

Table 2. Number of cells by each types of mesh

Fig. 6. Mesh around the catamaran hull

\begin{tabular}{lr}
\hline \multicolumn{1}{c}{ Type of Mesh } & $\frac{\text { No of Cells }}{250,599}$ \\
\hline Coarse - Mesh1 & $\frac{1}{\text { Medium - Mesh2 }}-\frac{1}{\text { Fine - Mesh3 } 278}$ \\
\hline
\end{tabular}

seconds - Fixed time step 1 per second) for each mesh.

Four thousand values of resistance were generated at the Light Load condition at $v=1.05$ $[\mathrm{m} / \mathrm{s}]$. Table 3 shows the average of the last five hundred values for the resistance of each mesh and its error when compared with an experimental value of $R_{\text {texp }}=1.79[\mathrm{~N}]$.

Table 3. Catamaran scale model dimensions

\begin{tabular}{|c|c|c|c|}
\hline & $\begin{array}{c}\text { Resistance } \\
\text { Average }\end{array}$ & \% Error & Sta. Dev. \\
\hline Mesh 1 & 2.22 & $24 \%$ & 0.71 \\
\hline Mesh 2 & 1.88 & $5 \%$ & 0.34 \\
\hline Mesh 3 & 1.91 & $6 \%$ & 0.50 \\
\hline
\end{tabular}

The errors between meshes 2 and 3 are closer. But, analyzing the standard deviation, Mesh 2 has less variation of resistance in the analyzed steps. Mesh 2 was selected to set up the other simulations. Fig. 6 represent the mesh 2 configuration around the hull.

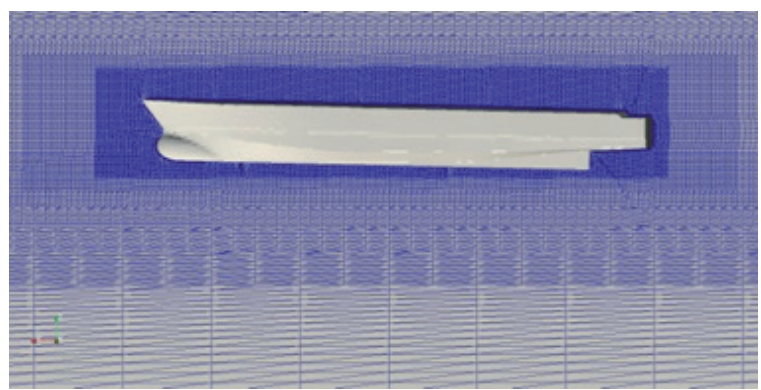

As a post-processing tool, $y^{+}$, was calculated to verify the mesh quality near the hull. A value of $y^{+}$ $\leq 100$ is acceptable for the case of the catamaran. Fig. 7 shows the wall $y^{+}$parameter for the submerged hull.

Fig. 7. $\mathrm{y}+$ of water, for ligth condition at $\mathrm{v}=1.05[\mathrm{~m} / \mathrm{s}]$

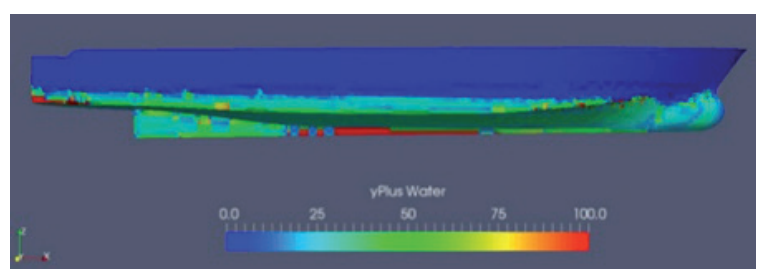

Bow, Stern and central keel are zones that required a grater mesh density.

\section{Resistance}

OpenFOAM calculate the forces components acting in Catamaran hull, namely pressure and 
Fig. 8. Resistance components at $\mathrm{v}=1.05[\mathrm{~m} / \mathrm{s}]$

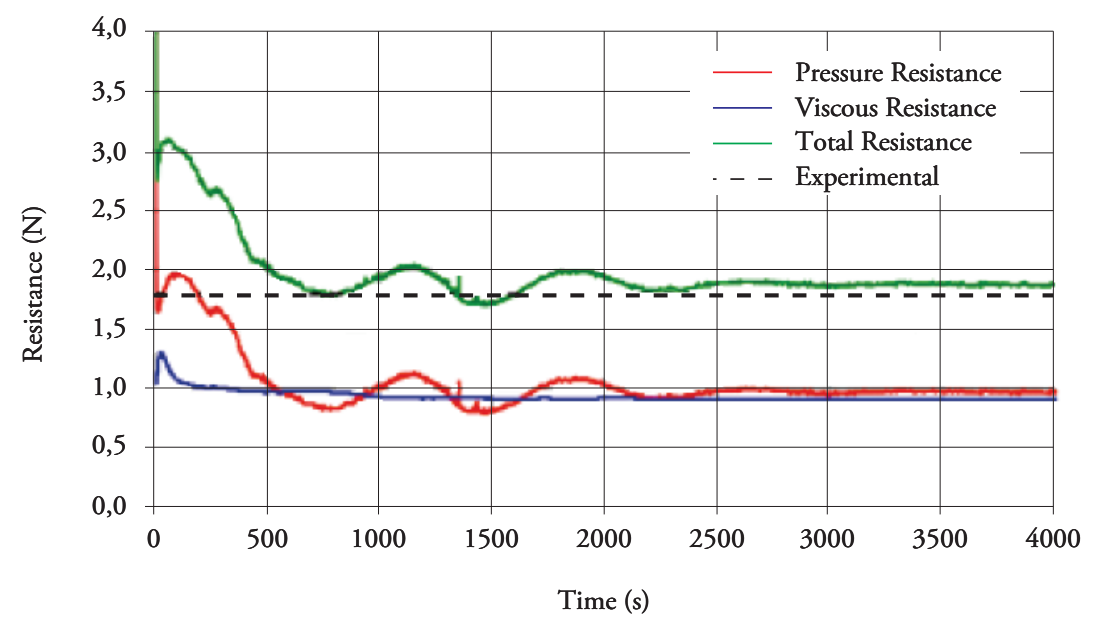

viscous. Fig. 8 shows Pressure and Viscous force components for the case of demi-hull in Light Condition at a velocity of $\mathrm{V}=1.05[\mathrm{~m} / \mathrm{s}]$. The experimental resistance is $1.79[\mathrm{~N}]$ at $\mathrm{Fn}=0.2453$.

Total resistance was obtained by adding pressure and viscous forces.

$$
\text { Sta.Dev. }=\frac{\text { Standard Deviation }}{\text { OpenFOAM average } R_{t}}
$$

Figs. 9 and 10 shows the total resistance by OpenFOAM, experimental data and Maxsurf for demi hull. The simulation standard deviation it's about $0.63 \%$, due this cannot be displayed.

\section{Demi Hull Catamaran Resistance}

The model was simulated following the experimental data [1], and compared with Maxsurf-Resistance. For demi hull Maxsurf-Resistance case, Holtrop method was used.

Table 4 and 5 present the data obtained by OpenFOAM simulations at different velocities in two Load Conditions. The percentage of standard deviation was obtained by [1]:

Table 4. OpenFoam Resistance data for demi hull in light condition

\begin{tabular}{|c|c|c|c|c|}
\hline Fn & $\begin{array}{c}\mathbf{V} \\
{[\mathrm{m} / \mathrm{s}]}\end{array}$ & $\begin{array}{c}\text { OF. } \\
\text { Rt [N] }\end{array}$ & $\begin{array}{c}\text { Exp. } \\
\text { Rt }[N]\end{array}$ & $\%$ Err \\
\hline 0.2453 & 1.05 & 1.88 & 1.79 & 5 \\
\hline 0.2663 & 1.14 & 2.15 & 3.91 & 45 \\
\hline 0.2803 & 1.20 & 1.16 & 3.60 & 68 \\
\hline 0.3037 & 1.30 & 2.81 & 5.26 & 47 \\
\hline 0.3387 & 1.4 & 3.54 & 7.01 & 49 \\
\hline
\end{tabular}

\section{Twin Hull Catamaran Resistance}

The model was simulated following the experimental data [1], and compared with MaxsurfResistance. To simulate the catamaran structure in OpenFOAM, the hull was displaced into the computational domain a distance $S=0.2805[\mathrm{~m}]$, measured from the centerline of ship to centerline of the hull, Fig. 11 shows the distribution.

Table 5. OpenFoam Resistance data for demi hull in load condition

\begin{tabular}{|c|c|c|c|c|}
\hline Fn & $\begin{array}{c}\mathbf{V} \\
{[\mathrm{m} / \mathrm{s}]}\end{array}$ & $\begin{array}{c}\text { OF. } \\
\text { Rt }[N]\end{array}$ & $\begin{array}{c}\text { Exp. } \\
\text { Rt }[N]\end{array}$ & $\%$ Err \\
\hline 0.2393 & 1.03 & 2.08 & 3.08 & 33 \\
\hline 0.2556 & 1.10 & 2.39 & 4.12 & 42 \\
\hline 0.2858 & 1.23 & 2.92 & 4.57 & 36 \\
\hline 0.3137 & 1.35 & 3.78 & 5.58 & 32 \\
\hline 0.3369 & 1.45 & 4.43 & 7.00 & 37 \\
\hline
\end{tabular}


Fig. 9. Total resistance for demi hull in light condition

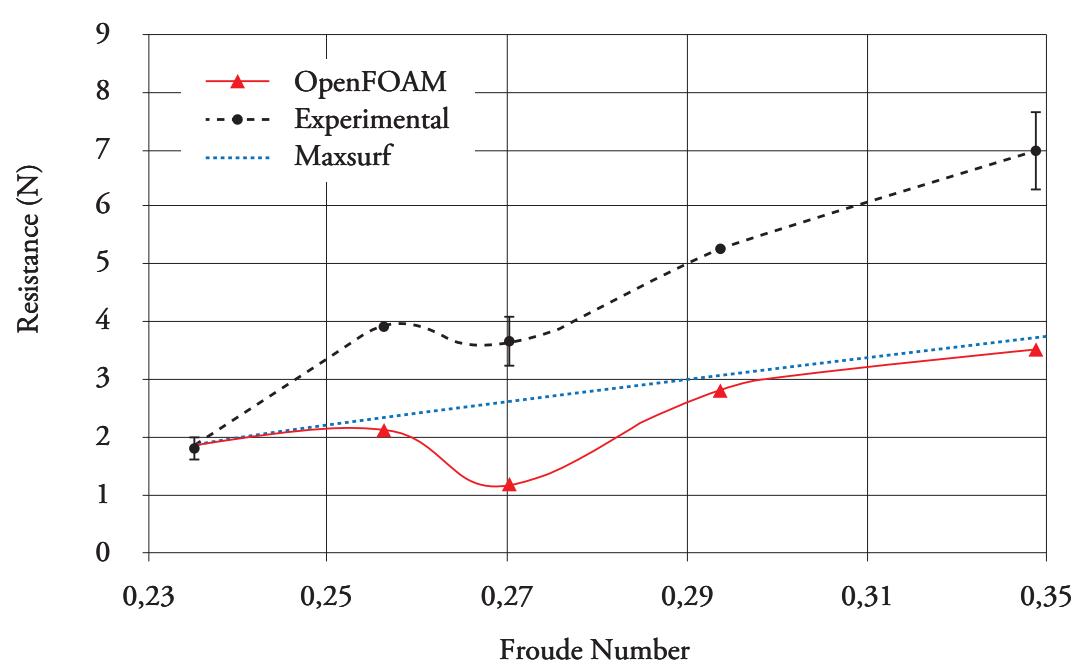

Fig. 10. Total resistance for demi hull in load condition

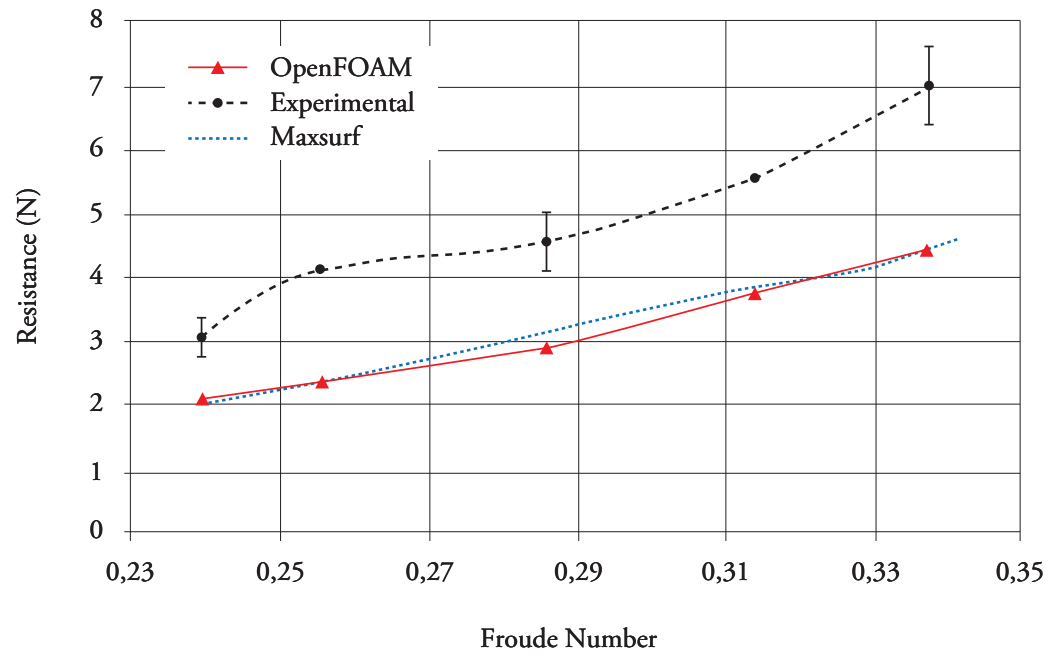

Fig. 11. Total resistance for demi hull in load condition

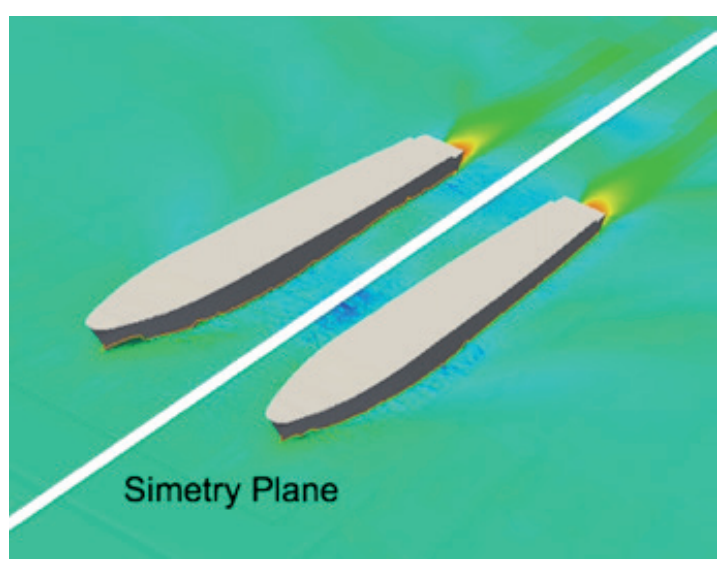


Table 6 and 7 present the data obtained by OpenFOAM simulations at different velocities in two Load Conditions.

Table 6. OpenFoam resistance data for twin hull in light condition

\begin{tabular}{|c|c|c|c|c|}
\hline Fn & $\mathbf{V}[\mathbf{m} / \mathbf{s}]$ & $\begin{array}{c}\text { OF. } \\
\mathbf{R t}[\mathbf{N}]\end{array}$ & $\begin{array}{c}\text { Exp. } \\
\text { Rt }[N]\end{array}$ & $\%$ Err \\
\hline 0.2453 & 1.05 & 3.87 & 5.11 & 24 \\
\hline 0.2663 & 1.14 & 4.51 & 4.80 & 6 \\
\hline 0.2943 & 1.26 & 5.36 & 6.14 & 13 \\
\hline 0.3083 & 1.32 & 6.08 & 7.76 & 22 \\
\hline 0.3574 & 1.53 & 8.01 & 10.32 & 22 \\
\hline 0.4111 & 1.76 & 11.97 & 12.07 & 1 \\
\hline 0.4532 & 1.94 & 15.40 & 13.29 & 16 \\
\hline
\end{tabular}

Figs. 12 and 13 shows the total resistance by OpenFOAM, experimental data and Maxsurf for demi hull.

Table 7. OpenFoam resistance data for twin hull in load condition

\begin{tabular}{|c|c|c|c|c|}
\hline Fn & $\mathrm{V}[\mathbf{m} / \mathbf{s}]$ & $\begin{array}{c}\text { OF. } \\
\text { Rt }[N]\end{array}$ & $\begin{array}{c}\text { Exp. } \\
\text { Rt }[N]\end{array}$ & $\%$ Err \\
\hline 0.2440 & 1.05 & 4.36 & 7.91 & 45 \\
\hline 0.2602 & 1.12 & 4.87 & 6.88 & 29 \\
\hline 0.2904 & 1.25 & 6.13 & 10.06 & 39 \\
\hline 0.3090 & 1.33 & 7.52 & 10.54 & 29 \\
\hline 0.3392 & 1.46 & 9.64 & 12.14 & 21 \\
\hline 0.3602 & 1.55 & 10.20 & 14.54 & 30 \\
\hline 0.4066 & 1.75 & 14.24 & 20.62 & 31 \\
\hline
\end{tabular}

Fig. 12. Total resistance for twin hull in light condition

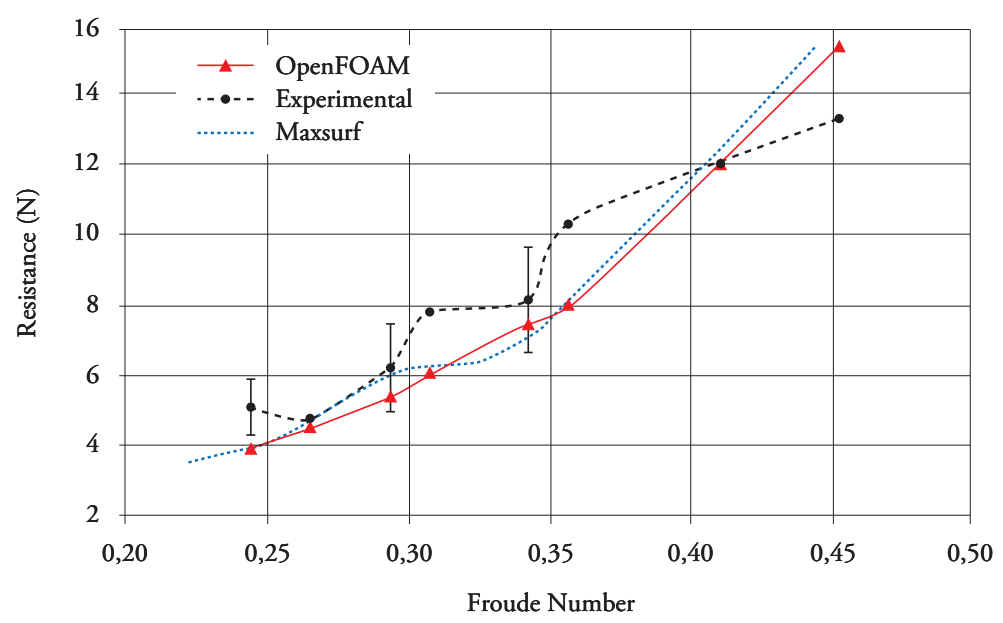

Fig. 13. Total resistance for twin hull in load condition

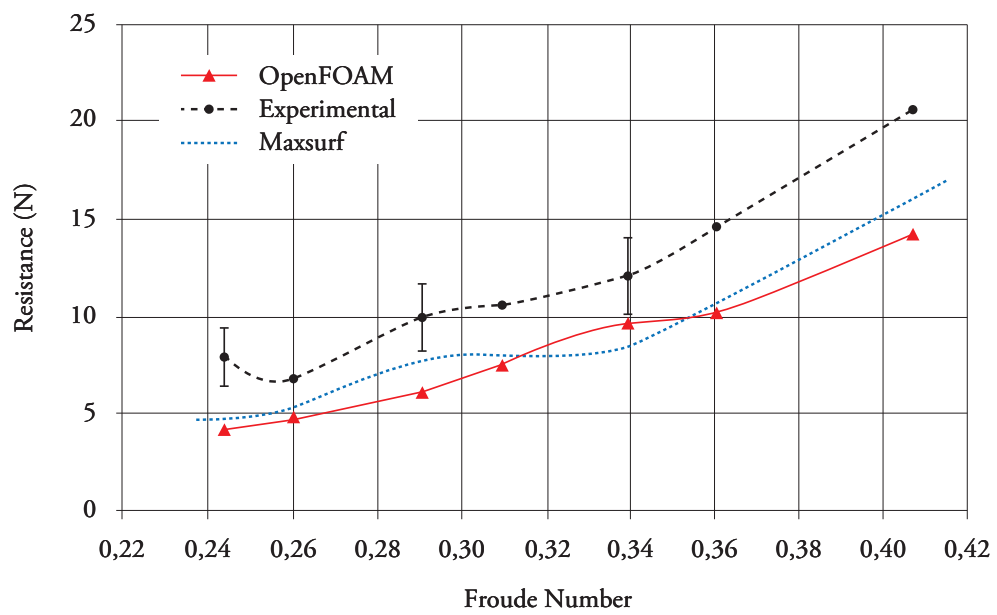


The errors between experimental data and numerical simulations are lower in light condition of catamaran. However none of the curves follows the same trend.

Fig. 14 shows the pressure distribution the hull for $\mathrm{Fn}=0.34(\mathrm{v}=1.45 \mathrm{~m} / \mathrm{s})$. The labels of dynamic pressure was setting to capture as blue ones the zones with negative pressure and red ones the zones with positive pressure. For twin hulls, the pressure in the inner side of the hull is slightly greater than the pressure on the outside of the hull; this is due to the interference caused by the other hull.

Fig. 14. Pressure around the bulbous for twin hull

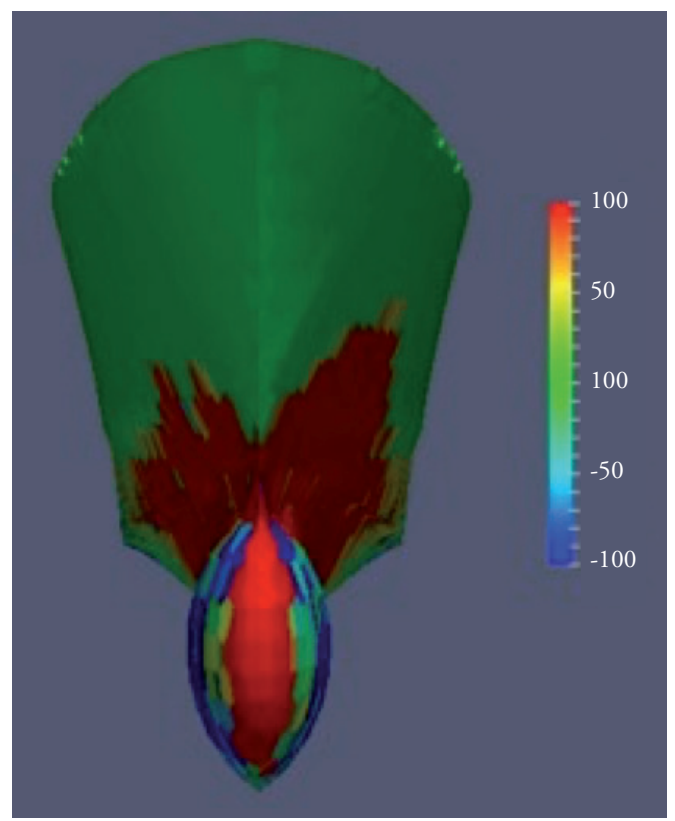

\section{Interference}

The catamaran interference was estimated following the expression [1]:

$$
R_{W}=\frac{R_{T C A T}-2 R_{T}}{2}
$$

Where:

$R_{W}$ is the demi hull interference in Newton

$R_{T C A T}$ is the total resistance of twin hulls in Newton

$R_{T}$ is the total resistance of demi hull in Newton

Figs. 15 and 16 shows the interference factor for original hull separation at Light and Full load conditions.

The interference factor obtained by numerical simulations is linear contrasting with the experimental interference published by Chávez and Lucín [1]. The positive interference corresponds to increased interference (unfavorable) and the negative values to decrease (favorable).

\section{Wave pattern}

Figs. 17 to 19 shows the wave pattern for different Froude numbers in Full load condition.

The blue areas correspond to the hollow of the wave and the red areas to the hump. Of these three

Fig. 15. Interference for light condition

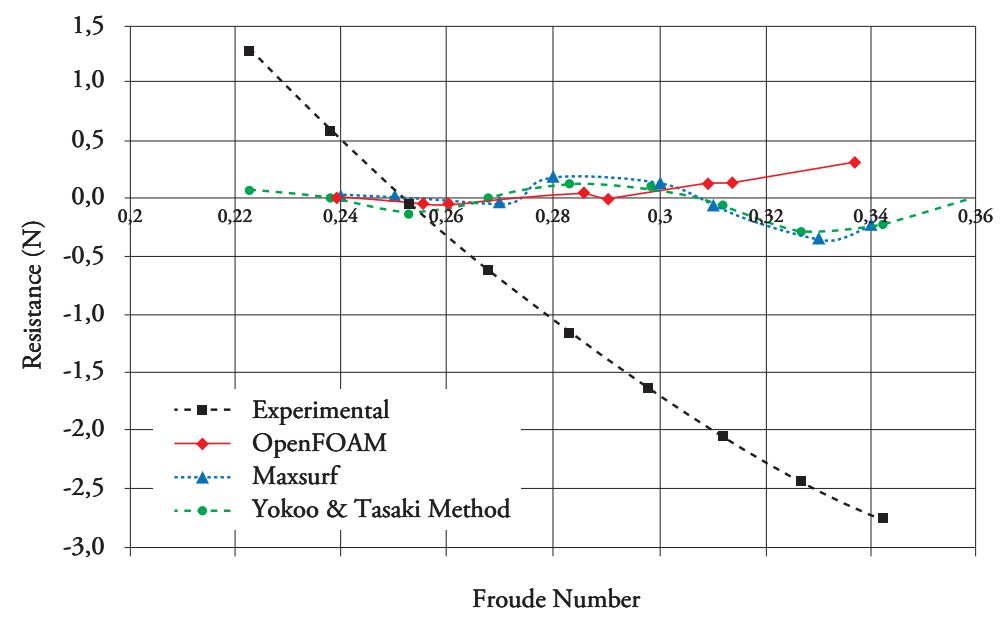


Fig. 16. Interference for load condition

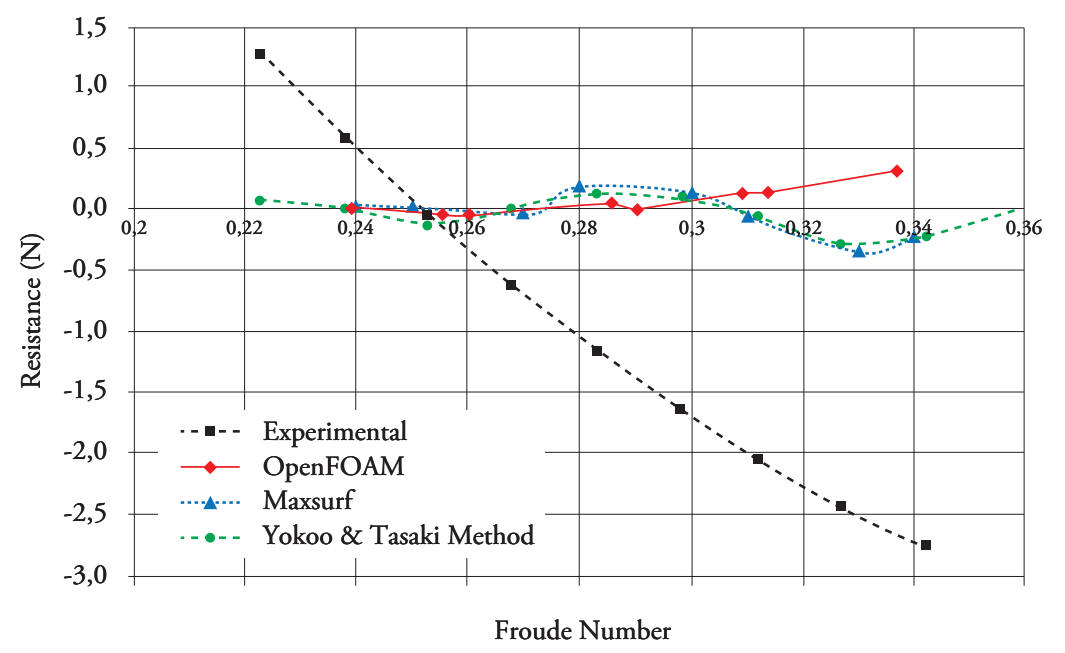

Fig. 17. Wave pattern at $\mathrm{Fn}=0.24$

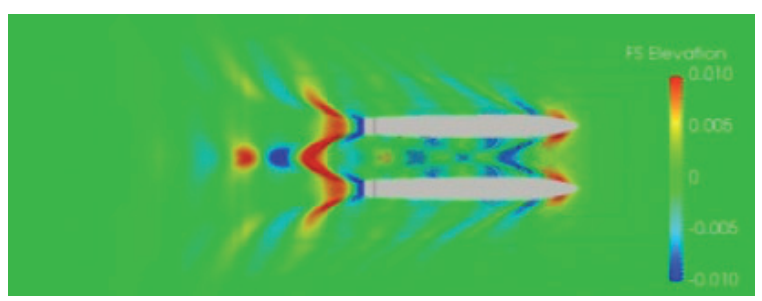

Fig. 18. Wave pattern at $\mathrm{Fn}=0.31$

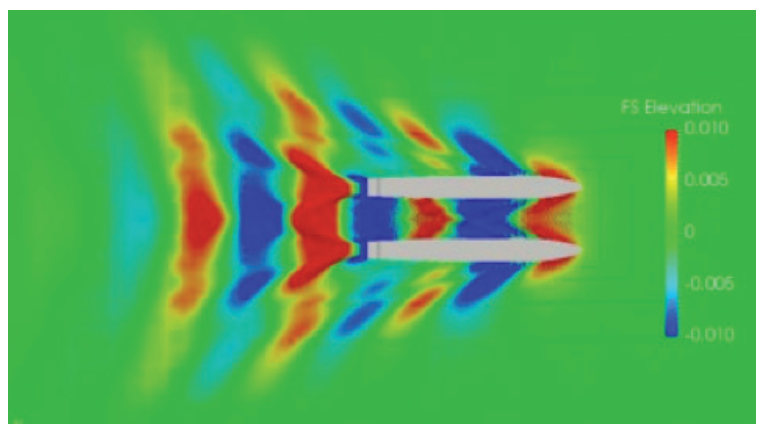

Fig. 19. Wave pattern at $\mathrm{Fn}=0.34$

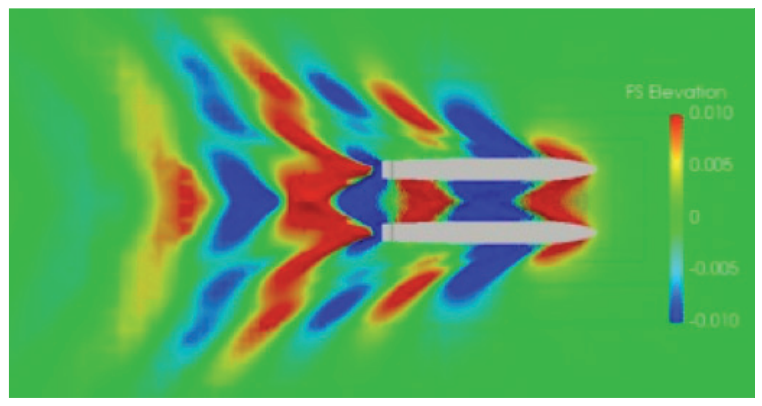

figures it is emphasized that as the speed of the simulation increases the amplitude and the length of the wave increase. Also, the wakes pattern from the lowest to the highest velocity produce the increase in zone of interference.

\section{Conclusions}

Before starting the Catamaran numerical resistance, several tutorials were carried out using the OpenFOAM user manual [6]. These tutorials were of great help to understand the capabilities and limitations of the software. Cavity was the first made tutorial, for laminar and incompressible flows. The user manual gives an overview of the workflow of OpenFOAM: Pre-processing, solution and Post-processing. ParaView is a post-processing tool; the user manual also gives an introduction of its operation. This was an important step for understanding OpenFOAM and the principles of fluid analysis.

A catamaran mesh convergence study was developed first, with 3 types of mesh for a demi hull at $\mathrm{Fn}=0.2453$. Mesh 2, with 1 million of cells, was chosen to the simulation because had the lowest error and standard deviation at $\mathrm{R}_{\text {texp }}=1.79$ $[N]$, error $=5 \%$ and Sta. Dev. $=0.34[N]$. Due the extensive time of resolution, the interDyMFOAM solver was not taken into consideration in the Catamaran hull. Two load conditions were 
implemented for demi and twin hulls. The errors for Light Load Condition were: $42.8 \%$ in Demi Hull and $14.0 \%$ in Twin Hull configurations. The errors for Full Load Condition were: $36.0 \%$ in Demi Hull and $32.0 \%$ in Twin Hull configurations.

Numerical simulations using OpenFOAM are a feasible method for predicting the resistance of the Cormorant Evolution catamaran, despite the difference between experimental data and numerical simulation resistance. However, numerical results are close to statistical methods, such as Holtrop and Molland, estimated with Maxsurf Resistance software.

The interference component between the twin hulls was estimated for Full and light Load conditions for Fn between 0.24 and 0.34. But these results were not those expected, because the curves of interference did not display the same trend. Also, the interference factor was calculated using the Maxsurf data and even though it was not very close, the Maxsurf interference had the same trend compared to numerical data.

These variations between experimental results and numerical simulations may be due to external factors, that can not be controlled or measured, such as: wind, water temperature, interference between the method of drag, towing velocity uncertainly, differences between the model and the catamaran, and range of work of Data Card available in our college.

\section{References}

[1] LUCÍN A. \& CHÁVEZ J. "Estudio experimental de la influencia de la separación de los cascos sobre la Resistencia en un catamarán de 32.5 metros”, 2012.

[2] HOlTROP J. \& MENNEN G.G.J. "An approximate power prediction Method", 1984.
[3] The Society of Naval Architects and Marine Engineers-SNAME, Principles of Naval Architecture, December 1966.

[4] Astillero y Marina BOTTO CIA. LTDA., Memoria Técnica del Catamarán "Cormotant Evolution”, 2010.

[5] Rhinoceros, Rhinoceros 5 - 90 days trial, https://www.rhino3d.com/es

[6] OpenFoam, The Open Source CFD Toolbox User Guide, Version 3.0.1, 13th December 2015.

[7] YOKOO K. \& TASAKI RYO, Technical Report No1: "On the twin hull ship" of the University of Michigan, 1951.

[8] BERTRAM V., Practical ship hyd ro dynamics, 2000.

[9] J. P. LAVAL. Unsteady Simulations on Turbulence Flows (DNS \& LES), Laboratoire de Mécanique de Lille (LML), CNRS. France 2006.

[10] PETROS VOXAKIS, Ship Hull Resistance Calculations Using CFD Methos, Naval Engineer and Master of Science in Mechanical Engineering at the Massachusetts Institute of Technology. May 2012.

[11] MENTER, F.R., KUNTZ, M. AND LANGTRY, R. TEN Years of industrial experience with the SST turbulence model. Turbulence, Head and Mass Transfer 4. Edited by K. Hanjalic, Y. Nagano, and M. Tummers. New York. 2003. 